\title{
Lexical competition effects in aphasia: Deactivation of lexical candidates in spoken word processing
}

\author{
Esther Janse * \\ Utrecht Institute of Linguistics OTS, Utrecht University, The Netherlands
}

Accepted 29 June 2005

Available online 11 August 2005

\begin{abstract}
Research has shown that Broca's and Wernicke's aphasic patients show different impairments in auditory lexical processing. The results of an experiment with form-overlapping primes showed an inhibitory effect of form-overlap for control adults and a weak inhibition trend for Broca's aphasic patients, but a facilitatory effect of form-overlap was found for Wernicke's aphasic participants. This suggests that Wernicke's aphasic patients are mainly impaired in suppression of once-activated word candidates and selection of one winning candidate, which may be related to their problems in auditory language comprehension.

(C) 2005 Elsevier Inc. All rights reserved.
\end{abstract}

Keywords: Inhibition; Aphasia; Auditory word recognition; Lexical processing; Negative priming; Lexical competition; Deactivation; Spoken word processing; Interference

\section{Introduction}

Aphasic patients have been shown to be impaired in speech perception and auditory comprehension tasks. Although identification of vowel contrasts is relatively unimpaired across aphasia types (Gow \& Caplan, 1996), problems with identification or discrimination of consonantal stimuli are relatively common. Reasonably, researchers have tried to relate perceptual deficits in acoustic-phonetic analysis to auditory speech comprehension deficits. Wernicke's aphasic patients in particular may experience severe speech comprehension problems. However, the link between (low-level) perceptual deficits and (higherlevel) speech comprehension is not at all clear-cut: several studies failed to find a strong relationship between perception ability and auditory speech comprehension (Basso, Casati, \& Vignolo, 1977; Blum-

\footnotetext{
${ }^{*}$ Fax: +31302536000 .

E-mail address: Esther.Janse@let.uu.nl.
}

stein, Cooper, Zurif, \& Caramazza, 1977; Csépe, Osman-Sági, Molnár, \& Gósy, 2001; Miceli, Gainotti, Caltagirone, \& Masullo, 1980; Yeni-Komshian \& Lafontaine, 1983). Therefore, acoustic-phonetic analysis impairments alone cannot explain the auditory speech comprehension problems encountered by aphasic patients, Wernicke's patients in particular.

Milberg, Blumstein, and Dworetzky (1988) investigated lexical access by presenting aphasic patients with pairs of words (primes and targets). Subjects were asked to perform lexical decision on the second member of the pair. The first words in the pair were systematically changed by one or more phonetic features (the items cat, gat, and wat as primes for the target dog). The non-brain-damaged control group showed a monotonically decreasing degree of facilitation as a function of phonological distortion. Participants with fluent aphasia, however, showed mediated semantic priming in all phonological distortion conditions (gat/ wat activating the lexical item cat, of which the activation then spreads to $d o g$ ), relative to the unrelated 
baseline. The nonfluent group, on the other hand, showed priming only in the undistorted related condition. On the basis of these results, Milberg et al. (1988) suggested that whereas the nonfluent aphasic participants seem to have reduced lexical activation, compared to an age-matched control group, the fluent aphasic participants have increased lexical activation (or 'overactivation').

Connine, Blasko, and Titone (1993) also performed a mediated semantic priming study (with non-braindamaged participants only) in which they varied the position of the changed phoneme and the phonological distance between the changed phoneme of a spoken non-word prime and the lexical item it is supposed to activate. As was found by Milberg et al. (1988), the size of the mediated priming effect depended on phonological distance in Connine et al. (1993). Mediated priming effects were found when the initial phoneme mismatch is minimal (e.g., only one phonetic feature). However, if the initial phoneme mismatch involves more than two phonological features (such as place, voicing, and manner features, e.g., the maximal mismatch prime ZANNER derived from MANNER), no cross-modal semantic priming was observed in Connine et al. (1993) (for, e.g., STYLE). This latter finding agrees with the results of Marslen-Wilson and Zwitserlood (1989) for initial maximal mismatches: no mediated priming effects was found for Dutch target bij ('bee') when rhyme word prime woning ('dwelling') or rhyme non-word prime foning were used to activate honing ('honey').

Gordon and Baum (1994) investigated whether the lack of mediated priming in nonfluent aphasic patients (Milberg et al., 1988) should be attributed to a lack of phonological priming or to the absence of (discernable) spreading of activation to semantic associates. Rhyme facilitation was found for the control group and for the nonfluent patient group. Leonard and Baum (1997) also found rhyme priming effects for a nonfluent patient group (blood facilitating lexical decision to flood, relative to an unrelated condition). The results of these latter two studies suggest that absence of mediated priming in the nonfluent patient group in the Milberg et al. (1988) study should be attributed to spreading of semantic activation, rather than to a lack of phonological priming. To replicate and extend the results of Gordon and Baum (1994), Baum (1997) investigated the effects of phonological, semantic, and mediated priming in control participants, fluent and nonfluent aphasic patients. Baum (1997) hypothesised that even if the control non-brain-damaged subjects do not exhibit mediated semantic priming, the fluent aphasics might, if lexical access of these patients should indeed be characterised as 'overactivation' (cf. Milberg et al., 1988). Importantly, however, no mediated priming was found in any of the subject groups, which contrasts with the Milberg et al. (1988) results. ${ }^{1}$

Yet, even though a lack of mediated priming for the nonfluent aphasic patients in Milberg et al. (1988) may not be decisive evidence, additional support for their proposal that nonfluent or Broca's aphasic patients suffer from a disturbance in the activation levels of lexical entries was found in later studies. Subphonetic variation has been found to affect lexical activation in that less prototypical stimuli produce a short-lived reduction in semantic priming for normal subjects, compared to more prototypical stimuli. Andruski, Blumstein, and Burton (1994) tapped lexical activation after the presentation of prototypical word forms such as cat (via lexical decision time to $d o g$ as a measure of activation of cat) and compared this to the amount of lexical activation elicited by acoustically degraded stimuli such as $c^{*} a t$ in which voice-onset time is manipulated to be closer to the voiced-voiceless boundary. Even though subjects would still classify the poorer phonetic exemplar sound as [k], the less prototypical word form $c^{*}$ at produced less priming than the unmanipulated cat, yielding evidence for initial gradedness of activation. Utman, Blumstein, and Sullivan (2001) reasoned that Broca's aphasic patients might be more vulnerable to such subphonetic variations. This was confirmed by their results with Broca's patients, but only in conditions of competition: subphonetic degradations resulted in an even greater reduction in lexical activation than found for control subjects when words such as $c^{*}$ oat were presented (having the competitor goat). When there was no voiced competitor $\left(c^{*} a t\right)$, a reduced priming effect was found for the Broca's aphasic patients, as was found for non-braindamaged subjects in the Andruski et al. (1994) study. Similar effects of acoustic degradation and lexical competition were found in Misiurski, Blumstein, Rissman, and Berman (2005) who included unimpaired listeners and Broca's aphasic patients. Mediated priming effects had been found with acoustically modified items such as $t^{*}$ ime (altered $[\mathrm{t}]$ being closer to the voiced phonetic category boundary) for normal listeners: presentation of somewhat intermediate forms not only activate the intended lexical form, but also the competitor. For the non-brain-damaged listeners, a reduced but significant semantic priming effect was found for penny (through partial activation of dime). However, Broca's aphasic participants did not show any mediated priming for targets preceded by altered primes. These results support the claim that Broca's aphasic patients show a general

\footnotetext{
${ }^{1}$ Additional evidence that spreading of semantic activation can only be measured reliably in conditions in which the prime word is activated to a relatively high degree can also be found in three doctoral dissertations. They report unsuccessful attempts to investigate activation of multiple word candidates by the presentation of partial primes (cut off before offset: Chwilla, 1996; Janse, 2003; Jongenburger, 1996).
} 
reduction of lexical activation which makes them particularly vulnerable to competition between acoustically similar lexical items.

Whereas later studies supported the characterisation of lexical access problems in Broca's aphasia as a general reduction of lexical activation, the 'overactivation' account of the fluent aphasic patients' performance (Milberg et al., 1988) proved problematic in several other studies. Baum (1997) found no mediated semantic priming effects for fluent aphasic patients: not in a condition in which the prime rhymed with an absent mediator word which was semantically related to the target (NEED-(READ)-BOOK), nor in a condition in which the prime was semantically related to an absent mediator word which rhymed with the target (SEE(LOOK)-BOOK). In Gordon and Baum's (1994) rhyme priming study, there was little evidence of rhyme facilitation of lexical decisions for fluent aphasics. Similarly, Baum's rhyme priming conditions (1997) did not support overactivation of phonological associates for fluent patients either. In a study on rhyme and repetition priming, Blumstein et al. (2000) found that Wernicke's aphasic patients showed a pattern similar to that of the non-brain-damaged control group: rhyme and identity priming effects were found, but slower response times in the rhyme than in the identity condition. Thus, lexical access impairments for Wernicke's patients are less clear. It is important to note that discrepancies among studies could be due (partly) to different ways of selecting and classifying aphasic patients. Aphasic patients may be clinically diagnosed as Broca's or Wernicke's, or as fluent/nonfluent. This does not always yield the same classification: not all nonfluent aphasic patients are Broca's and not all fluent aphasic patients are Wernicke's. Different result patterns may therefore reflect different types of patients.

There are, however, some indications that the problem in Wernicke's aphasia may reside in that aspect of lexical access involving competition between already activated lexical entries. Initial activation may be broad, but competition between more and less appropriate candidates (in terms of bottom-up support) should result in one winning candidate. Most researchers on spoken word access processes now agree that lexical access involves continuous activation of multiple candidate words, and that there is a competition process between the activated candidates yielding the eventual winning words (cf. McQueen \& Cutler, 2001 for references). In word recognition models like Shortlist (Norris, 1994), two mechanisms of lexical selection have been proposed: bottom-up inhibition and lateral inhibition. Bottom-up inhibition depends on mismatching information: depending on phonological distance to the target, mismatching information results in a certain amount of deactivation. Second, lateral inhibition between compet- itors allows the best-fitting and most-activated candidates to inhibit and deactivate the weaker ones.

Yee, Blumstein, and Sedivy (2004) performed an eye-tracking experiment and investigated how long participants were distracted by onset-overlapping words when presented with auditory input. In this task, the participants's eye movements are monitored when they are asked to select the picture from a four-picture display. When presented with hammock, participants may initially fixate on the picture of a hammer (being an onsetoverlapping competitor). In the mediated semantic competitor condition, upon hearing hammock, they may initially fixate on a distractor object that is semantically related to an onset competitor of the uttered word (fixate on nail, being semantically related to onset-overlapping competitor hammer). Yee et al. (2004) tested Broca's aphasic patients, Wernicke's patients and control adults. The results showed onset competitor and mediated semantic competitor effects for the control adults: they fixated longer on competitor pictures (or on items semantically related to onset competitors) than on unrelated distractor pictures. The Broca's aphasic patients showed only a weak and insignificant competitor effect for the onset-overlapping competitor, which agrees with the account that their activation levels are overall reduced. Wernicke's aphasics, however, were significantly more likely to fixate on onset competitors than on unrelated distractors and also preferentially fixated on distractors that were semantically related to the onset competitor. Most importantly, these competitor effects appeared larger in Wernicke's aphasics compared to the age-matched control subjects. This increased effect of onset competitors for Wernicke's patients suggests that deactivation of word candidates that no longer match the incoming auditory input is delayed for Wernicke's patients.

Further evidence for impaired deactivation as the core problem in Wernicke's aphasia comes from an adapted Stroop Colour-Word test by Wiener, Connor, and Obler (2004). The Stroop interference effect, measured in terms of response times and error rates, reflected the inability to effectively ignore an automatically evoked distracting stimulus: participants were instructed to press the key that corresponded to the number of items on the screen (e.g., compatible condition: "333" or incompatible condition: "3333", compared to neutral conditions "XXX" or "XXXX"). Theories of selective attention have shown that older adults show poorer inhibitory control than younger adults (Hasher \& Zacks, 1988), but importantly, Wiener et al. (2004) showed that the interference effect was significantly larger for Wernicke's aphasic patients than for an age-matched control population. Importantly, facilitation effects in the compatible condition (relative to neutral condition) were equivalent for the two subject groups (Wernicke's patients and the 
control population), which indicates that the difference in interference cannot be attributed to generalised slowing.

In summary, these studies suggest that the problem in Wernicke's aphasia, rather than in the reduced levels of activation in Broca's aphasia, may reside more in impaired deactivation of once-activated lexical entries. The present study was set up to gather more evidence for this idea. Note, however, that impaired deactivation cannot be distinguished from the overactivation account given by Milberg et al. (1988): it is not clear whether less appropriate lexical items receive too much initial activation, or remain highly activated because they are not depressed. The present study was set up from a slightly different angle in order to investigate the competition and deactivation process of lexical candidates that were initially appropriate. Previous research with non-brain-damaged listeners has shown that form-overlap between a prime and a following target lexical item may affect the speed with which the target item can be processed. Initial overlap can lead to inhibition when the overlap consists of at least two phonemes (Monsell \& Hirsch, 1998; Slowiaczek \& Hamburger, 1992). This high-similarity interference effect can be attributed to lateral inhibition between competing word candidates, or to bottom-up inhibition following mismatching information (these two effects cannot be distinguished here, cf. Frauenfelder, Scholten, \& Content, 2001). An increase in the level of activation of one candidate then automatically leads to a decrease in the activation level of others. Once one of the candidates has been isolated and recognised, the other candidates are decreased in activation. This 'winner-takes-all' principle is argued to make the recognition process more efficient (McClelland \& Elman, 1986).

Now, if the activation level of the candidates is not perfectly regulated depending on the goodness-of-fit, competition between activated items might be problematic. In particular, if the competition process is impaired, once-activated candidates may still be active at a point at which they should have been long deactivated because they no longer fit the incoming information.

This paper aims at investigating just this issue: can lexical competition or inhibition effects be found in aphasia? Second, how do the results of two patient groups (Broca's vs. Wernicke's patients) compare? Given the different results for the two patient groups in Milberg et al. (1988) and Yee et al. (2004), and given the results of Wiener et al. (2004), different patterns are predicted with respect to inhibition of co-activated candidates. Whereas Broca's patients are impaired in lexical access, the problem for Wernicke's aphasic patients seems to be for their recognition system to settle on the most compatible candidate and to discard the less appropriate ones. Therefore, no inhibition is predicted for the Wernicke's patients, and co-activated candidates may even be facilitated.

For the Broca's patients, a smaller amount of inhibition is predicted than for the control participants. If Broca's patients have higher activation thresholds, activation levels are reduced initially. Aydelott Utman et al. (2001) showed that Broca's patients need a relatively large amount of positive evidence in order to surpass the activation thresholds: if there is an initial acoustic mismatch and there is a close competitor, access can quite easily be blocked, but when the mismatch occurs only word-finally, evidence has already built up for a certain candidate. Thus, small inhibition effects might be found for Broca's aphasic participants if the amount of overlap between the intended word and the co-activated word is large enough to surpass the activation threshold (cf. also the weak onset-competitor effects in Yee et al., 2004). Based on the assumption that the size of the deactivation effect is proportional to the competitor's activation before the deviation point, the inhibition effect is predicted to be smaller than that for the control participants because of reduced activation levels.

To confirm and extend the account that the dynamics of lexical activation are differentially affected in Broca's and Wernicke's aphasia, this study focuses on a different aspect of the word recognition process. Competition between lexical candidates was investigated by using the lexical decision paradigm with initial form-overlap between prime and target, rather than rhyme overlap between prime and target (as in most lexical access studies with aphasic patients). Inhibition effects were predicted for the normal control group and for Broca's aphasic participants, but not for the Wernicke's aphasic participants.

\section{Method}

\subsection{Participants}

Three groups of participants were tested: 8 Broca's patients, 6 Wernicke's patients, and 11 control subjects. Mean age was 53 years for the Broca's aphasic patients, 62 for the Wernicke's aphasic patients, and 61 for the control adults. All patients became aphasic as a consequence of a CVA and were classified as either Broca's or Wernicke's aphasic patients according to the Dutch version of the Aachen Aphasia Test (Graetz, de Bleser, \& Willmes, 1992). This diagnosis was confirmed by the speech therapist. One of the Wernicke's aphasic patients (W6), however, was diagnosed as a true Wernicke's aphasic by the speech therapist, but as a global aphasic patient by the Aachen Aphasia Test. Results will be discussed including this patient and excluding this patient.

The patients were recruited via several rehabilitation centres in the Netherlands and volunteered for the study 
Table 1

Patient information

\begin{tabular}{|c|c|c|c|c|c|}
\hline Identity & Age & Sex & Etiology & $\begin{array}{l}\text { Months } \\
\text { post-onset }\end{array}$ & $\begin{array}{l}\text { AAT language comprehension } \\
\text { score }(0-120)\end{array}$ \\
\hline B1 & 58 & $\mathrm{~F}$ & L CVA & 7 & 60 \\
\hline B2 & 75 & $\mathrm{~F}$ & L CVA (arteria cerebri media) & 16 & 75 \\
\hline B3 & 51 & $\mathrm{~F}$ & L CVA (frontoparietal) & 20 & 82 \\
\hline B4 & 56 & M & L CVA (parietal) & 8 & 110 \\
\hline B5 & 54 & M & L CVA & 17 & 102 \\
\hline B6 & 53 & M & L CVA & 3 & 74 \\
\hline B7 & 36 & $\mathrm{~F}$ & L CVA (arteria cerebri media) & 3 & 62 \\
\hline B8 & 39 & $\mathrm{~F}$ & L CVA (arteria cerebri media) & 5 & 111 \\
\hline W1 & 54 & $\mathrm{~F}$ & L CVA & 11 & 60 \\
\hline W2 & 60 & M & L CVA & 4 & 14 \\
\hline W3 & 39 & $\mathrm{~F}$ & $\begin{array}{l}\text { L CVA (aneurysma arteria } \\
\text { communicans posterior) }\end{array}$ & 15 & 90 \\
\hline W4 & 68 & M & L CVA & 7 & 94 \\
\hline W5 & 76 & $\mathrm{~F}$ & L CVA & 7 & 79 \\
\hline W6 & 75 & $\mathrm{~F}$ & L CVA & 6 & 53 \\
\hline
\end{tabular}

after giving informed consent. The design and procedure of this multi-center experiment was approved by the Medical Ethics Committee of the Groningen University Medical Center. Table 1 provides a summary of age, sex, post-onset time, etiology, and scores for language comprehension (as part of the Aachen Aphasia Test).

\subsection{Material}

In connectionist models of spoken-word recognition, such as TRACE (McClelland \& Elman, 1986), the size of phonological or semantic priming effects depends on the number of active competitors and their relative frequencies. It makes sense that the same goes for competitor effects: the longer a competitor competes with the target word, the fiercer the competition. If only one competitor is still in the race at the time the disambiguating information arrives, the activation-depression effect for that single competitor will be larger than if there are still four active competitors. This was in fact shown by Dufour and Peereman (2003) who found that the magnitude of the inhibitory priming effect is determined by the size of the competitor set. Therefore, 30 polysyllabic prime-target pairs (primes and targets being polysyllabic), instead of monosyllabic, were chosen to have a substantial number of overlapping phonemes, and at the same time a reduced cohort of potential word candidates before the deviation point.

All word materials were in Dutch, and form-overlap between prime and target was always initial. All targets were presented in two conditions: (1) a control condition, in which the target is preceded by a non-overlapping, unrelated prime (e.g., trisyllabic prime methode 'method' precedes trisyllabic target salami 'salami'), and (2) an overlap condition, in which the target is preceded by a phonologically related prime (e.g., trisyllabic prime salaris 'salary' precedes target salami 'salami').
All prime-target pairs shared the same stress pattern and syllable number in both conditions. Since lexical stress plays a role in lexical access (Cutler \& van Donselaar, 2001), segmentally overlapping items that have a different stress pattern cannot be regarded as active competitors to the target. The mean number of overlapping initial phonemes in the overlap condition was 3.5 (range 2-5) and mean number of phonemes in targets 5.7 (range 4-7). The mean size of the cohort of word candidates, evaluated before the deviation point (i.e., the first phoneme to make the word unique), was 2.3 (range 1-6).

The 30 target items (presented twice), 30 control primes, and 30 form-overlap primes all required a YES response. Additional filler items were included, so that the subjects would have to give a 'NO' response equally often as a 'YES' response during the experiment. Intervening fillers did not share initial (or final) overlap with nearby primes or targets. Filler items consisted of 65 non-words and 5 real words to balance for the 60 YES responses to primes and targets in each block (cf. Section 2.3). Fillers were repeated in the second block (as were the targets), beit in a different order. This ensured that subjects could not anticipate a specific target from the non-words preceding it. Additionally, 10 practice items (also balanced for lexical status) were recorded to familiarise the participants with the task of lexical decision.

The isolated words were read by a male native speaker of standard Dutch with a clear speaking style. The materials were recorded on digital audiotape with a Sennheiser microphone. They were fed as digital input into the computer, downsampled to $16 \mathrm{kHz}$, and each word was stored as a separate sound file.

\subsection{Procedure}

A within-subject design was chosen because of the low number of aphasic patients and because each 
participant ought to be his or her own control, given the variability in performance between aphasic participants. The experiment consisted of two blocks: half of the targets were presented in the overlap condition in block A, and in the control condition in the second block $\mathrm{B}$, for the other half of the targets the order was reversed. Furthermore, half of the subjects in each group was presented with the block order $\mathrm{AB}$, the other half with the reverse order BA. This ensured that any differences between overlap and control conditions would not be confounded with possible order-item interaction effects.

Listwise presentation with continuous lexical decision was used, and intervening filler items were placed in between prime and target (cf. Monsell \& Hirsch, 1998). Pairwise presentation of primes and targets involves the choice for an interstimulus interval of a specific duration. Prather, Zurif, Love, and Brownell (1997) showed that lexical priming effects for a nonfluent aphasic patient occurred at a much later ISI than the interval at which normal elderly subjects showed priming. However, an ISI that would be sufficiently long for the aphasic patients might already induce expectancy-based strategies in the control group because prime-target manipulations can be rather obvious to subjects when prime and target are presented as a pair (cf. Neely \& Keefe, 1989). In a listwise presentation, subjects can be given sufficient time to process each item, and they are less aware of specific relations between items, so that they are less likely to develop strategic response behaviour. Although the time course of lexical activation and deactivation in aphasia is an important issue, this study was not set up to check when deactivation occurs, but whether it occurs (within the time span of several seconds).

To avoid a certain recurrent YES/NO response pattern, the number of intervening items varied and ranged from one to five (in both conditions, the mean number of items intervening between prime and target was 2.2).

Participants were seated at a table, wearing closed earphones. The experimental software programme TEMPO (Motta, Rizzo, Swinney, \& Piñango, 2000) was used to present the subjects with the materials. Participants were asked to give a lexical decision response after each auditory presentation by pressing either of two buttons on a response box. There was a $3 \mathrm{~s}$ window during which the response could be given. Even if no response was given, the experiment proceeded following a $1 \mathrm{~s}$ pause before the next trial. During the practice session, meant to familiarise participants with the task, each participant's performance was monitored. All participants (control and aphasic) were instructed to respond with their non-dominant hand for both a YES response and a NO response and to respond as quickly and as accurately as possible. They were also told that they could not correct their response once given. The experiment lasted about $25 \mathrm{~min}$. Participants were given a short break half-way through the experiment.

\section{Results}

Table 2 below lists the percentages of correct lexical decisions, broken down by primes and targets and by participant group. For the Wernicke's aphasic patients, accuracy rates are given including patient $\mathrm{W} 6$, but also excluding patient $\mathrm{W} 6$.

First, lexical decision accuracy rates for the targets were analysed to investigate the effect of Condition (overlap vs. unrelated) and of Subject Group. Accuracy rates were arcsine transformed. Because patient W6 showed a markedly lower accuracy, her data were left out of the accuracy analysis. ${ }^{2}$ The effect of Condition was significant only by items $\left(F_{1}(1,21)=2.05, p>.1\right.$; $\left.F_{2}(1,29)=4.29, p=.047\right)$. The effect of Subject Group was not significant, indicating that the aphasic patients did not perform worse than the control adults $\left(F_{1}(2,21)<1, n s ; F_{2}(2,28)=1.56, p>.1\right)$. The interaction between Condition and Subject Group was not significant either $\left(F_{1}(2,21)<1, n s ; F_{2}(2,28)<1, n s\right)$.

The use of listwise presentation of primes and targets with continuous lexical decision enables inspection of lexical decision performance to the primes as well: accuracy rates were also established for the primes (cf. Table 2) to investigate the effect of Subject Group (again, data of patient W6 were excluded from this analysis). The effect of Subject Group on the arcsine transformed rates was significant $\quad\left(F_{1}(2,21)=4.27, \quad p=.028\right.$; $\left.F_{2}(2,58)=13.21, p<.001\right)$. Post hoc analyses (Bonferroni test) showed that the Broca's aphasic patients had a lower accuracy than the other two participant groups, the differences between the control group and the Broca's aphasic patients were significant $(p=.025$ by subjects; $p=.001$ by items); and the difference between the two patient groups was significant only by items ( $p>.1$ by subjects; $p=.002$ by items); but there was no difference between the control group and the Wernicke's aphasic patients ( $p>.1$ in both analyses).

For the response time analyses, only correct YES responses were included. Mean response times to the targets in both conditions are shown in Fig. 1. In Table 3 individual performance is shown for each participant in all three groups (mean RT and number of valid responses). In Fig. 1 and Table 3, response times in either condition are collapsed over first or second presentation. In Fig. 2, the repetition effect can be seen: response times

\footnotetext{
${ }^{2}$ When the accuracy data of patient W6 are included, the accuracy results show a similar pattern: effects of Condition and Subject group both not significant, and Condition $\times$ Subject Group interaction not significant.
} 
Table 2

Lexical decision accuracy rates for primes and targets (targets in either condition) for the three subject groups

\begin{tabular}{llll}
\hline & \multicolumn{3}{l}{$\%$ correct in lexical decision task } \\
\cline { 2 - 4 } & Primes & $\begin{array}{l}\text { Targets following } \\
\text { control prime }\end{array}$ & $\begin{array}{l}\text { Targets following } \\
\text { overlap prime }\end{array}$ \\
\hline Control adults & 99 & 98 & 98 \\
Broca's & 95 & 97 & 96 \\
$\begin{array}{l}\text { Wernicke's } \\
\quad \text { (including W6) }\end{array}$ & 92 & 92 & 87 \\
$\begin{array}{c}\text { Wernicke's } \\
\quad(\text { excluding W6) }\end{array}$ & 98 & 98 & 95 \\
\hline
\end{tabular}

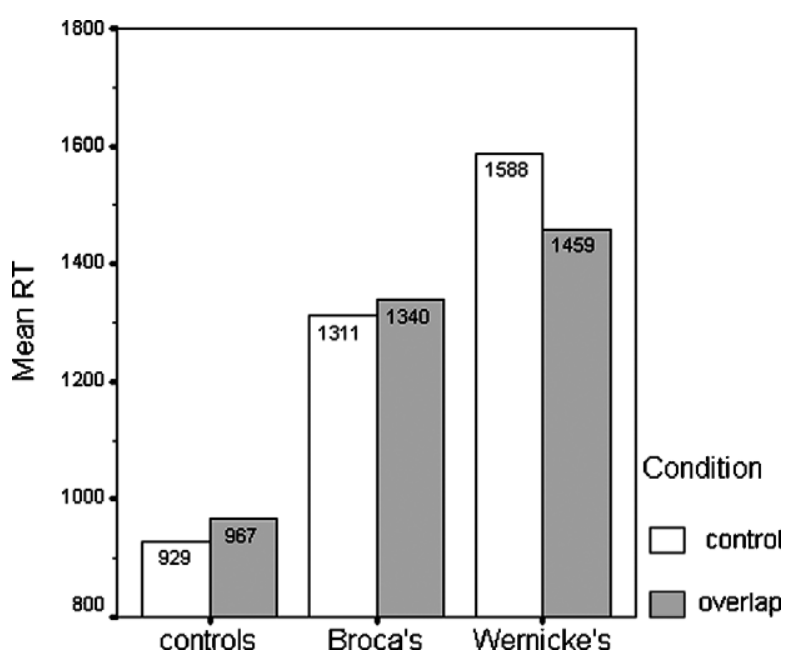

Fig. 1. Mean response time to targets in control and inhibition (overlap) condition for the three subject groups.

are presented for the first and second presentations (but now collapsed over control and overlap condition).

First, overall analyses will be given to compare performance between subject groups. The raw lexical decision times (measured from target onset) were transformed to inverse response times (1/RT) to make the data distribution less skewed (Ulrich \& Miller, 1994). These inverse response times were fed into two ANOVAs, by subjects (nested under Subject Group) and by items, respectively, to test the effects of Subject Group, Condition (control vs. overlap condition), and Presentation (first or second presentation of the same target item). The results of the one Wernicke's patient (W6) with an uncertain diagnosis were left out of these analyses. The effect of Subject Group was highly significant $\quad\left(F_{1}(2,21)=15.72, \quad p<.001\right.$; $\left.F_{2}(2,28)=299.11, p<.001\right)$. Post hoc comparisons for this Subject Group effect (Bonferroni) showed that the two aphasic patient groups each responded significantly slower to the targets than their age-matched controls $(p<.001$ by subjects and by items), and that there was no overall difference between the two patient groups. There was no significant main effect of Condition $\left(F_{1}(1,21)=1.24, n s ; F_{2}(1,29)<1, n s\right)$, but the effect of Presentation was significant $\left(F_{1}(1,21)=27.24 ; \quad p<.001\right.$;
Table 3

Individual lexical decision performance of all participants: response times to targets and number of valid responses in both test conditions

\begin{tabular}{|c|c|c|c|c|}
\hline & \multicolumn{2}{|c|}{ Unrelated condition } & \multicolumn{2}{|c|}{ Overlap condition } \\
\hline & $\begin{array}{l}\text { Mean RT } \\
(\mathrm{ms})\end{array}$ & $\begin{array}{l}\text { Count } \\
\text { (out of 30) }\end{array}$ & $\begin{array}{l}\text { Mean } \\
\text { RT (ms) }\end{array}$ & $\begin{array}{l}\text { Count } \\
\text { (out of 30) }\end{array}$ \\
\hline \multicolumn{5}{|l|}{ Control adults } \\
\hline $\mathrm{C} 1$ & 796 & 28 & 840 & 28 \\
\hline $\mathrm{C} 2$ & 888 & 30 & 941 & 29 \\
\hline C3 & 958 & 29 & 1043 & 29 \\
\hline $\mathrm{C} 4$ & 862 & 29 & 910 & 28 \\
\hline $\mathrm{C} 5$ & 867 & 29 & 891 & 30 \\
\hline C6 & 891 & 30 & 904 & 30 \\
\hline $\mathrm{C} 7$ & 940 & 30 & 969 & 30 \\
\hline $\mathrm{C} 8$ & 853 & 30 & 915 & 29 \\
\hline $\mathrm{C} 9$ & 1021 & 30 & 1060 & 30 \\
\hline $\mathrm{C} 10$ & 954 & 30 & 1003 & 30 \\
\hline $\mathrm{C} 11$ & 1175 & 30 & 1153 & 30 \\
\hline Control mean & 929 & 29.5 & 967 & 29.4 \\
\hline \multicolumn{5}{|l|}{ Broca's patients } \\
\hline $\mathrm{B} 1$ & 1199 & 29 & 1197 & 30 \\
\hline B2 & 1319 & 28 & 1309 & 28 \\
\hline B3 & 1206 & 28 & 1438 & 30 \\
\hline B4 & 1725 & 30 & 1661 & 30 \\
\hline B5 & 1496 & 28 & 1610 & 24 \\
\hline B6 & 1291 & 30 & 1225 & 30 \\
\hline B7 & 1136 & 30 & 1231 & 29 \\
\hline B8 & 1121 & 30 & 1094 & 30 \\
\hline Broca's mean & 1311 & 29.1 & 1340 & 28.9 \\
\hline \multicolumn{5}{|c|}{ Wernicke's patients } \\
\hline W1 & 1586 & 30 & 1400 & 27 \\
\hline W2 & 2276 & 29 & 2174 & 27 \\
\hline W3 & 914 & 30 & 892 & 30 \\
\hline W4 & 1305 & 29 & 1211 & 29 \\
\hline W5 & 1613 & 29 & 1530 & 29 \\
\hline W6 & 1999 & 19 & 1772 & 14 \\
\hline $\begin{array}{r}\text { Wernicke's mean } \\
\text { (including W6) }\end{array}$ & 1588 & 27.7 & 1459 & 26.0 \\
\hline $\begin{array}{l}\text { Wernicke's mean } \\
\text { (excluding W6) }\end{array}$ & 1535 & 29.4 & 1428 & 28.4 \\
\hline
\end{tabular}

$\left.F_{2}(1,29)=80.54, \quad p<.001\right)$. Crucially, the interaction between Condition and Subject Group was significant $\left(F_{1}(2,21)=5.88, p=.003 ; F_{2}(2,28)=12.04, p<.001\right)$. All other interactions were not significant.

The results were also analysed separately for each Subject Group (Univariate ANOVAs by subjects and items) to analyse what contributed to the Subject Group $\times$ Condition interaction. For the control adults, the effect of Condition was significant $\left(F_{1}(1,10)=39.30\right.$, $\left.p<.001 ; F_{2}(1,29)=15.19, p=.001\right)$ : responses to the targets were significantly slower in the overlap condition $(967 \mathrm{~ms})$ than in the control condition $(929 \mathrm{~ms})$. The effect of Presentation was also significant $\left(F_{1}(1,10)=6.48\right.$, $\left.p=.029 ; F_{2}(1,29)=23.30, p<.001\right)$ : responses were generally faster when targets were presented for the second time. The interaction between Condition and Presentation was not significant ( $p>.1$ in both analyses). 
The Broca's aphasic participants as a group showed no significant effect of Condition $\left(F_{1}(1,7)=1.52, p=.26\right.$; $\left.F_{2}(1,29)<1, n s\right)$. Insofar as there is a trend, it is in the predicted direction: response times are somewhat slower in the overlap condition $(1340 \mathrm{~ms})$ than in the control condition (1311 ms; cf. Fig. 1 and Table 3). This confirms the prediction that the inhibition effect would be weaker for this group than for the control participant group. Note, however, that the Broca's aphasic participants show a great deal of individual variability (cf. Table 3 ). The effect of Presentation was significant only by items $\left(F_{1}(1,7)=2.37, p=.17 ; F_{2}(1,29)=20.36, p<.001\right)$. The interaction between Condition and Presentation was not significant ( $p>.1$ in both analyses).

The Wernicke's aphasic participants showed a significant effect of Condition $\left(F_{1}(1,5)=17.56, \quad p=.003\right.$; $\left.F_{2}(1,29)=4.07, \mathrm{p}=.053\right)$, but note that responses were faster in the overlap condition $(1450 \mathrm{~ms})$ than those in the control condition (1602 ms). As was found for the Broca's aphasic participants, the effect of Presentation was significant only by items $\left(F_{1}(1,5)=4.02, p=.10\right.$; $\left.F_{2}(1,29)=20.16, p<.001\right)$. There was no interaction between Condition and Presentation. If the results of the one Wernicke's patient (W6) are excluded who was diagnosed as 'global' in the AAT, the results change only slightly. Mean response time is then $1535 \mathrm{~ms}$ in the control/unrelated condition (based on $98 \%$ correct lexical decisions), and $1428 \mathrm{~ms}$ in the overlap condition $(95 \%$ correct lexical decisions).

An alternative explanation for the faster response times in the overlap condition for the Wernicke's aphasic patients would be a speed-accuracy trade-off. However, the accuracy rate analyses for the targets showed no Subject Group $\times$ Condition interaction. This renders a speedaccuracy trade-off rather unlikely. The Condition effect is significant by subjects and marginally significant by items $\left(F_{1}(1,4)=14.60, p=.019 ; F_{2}(1,29)=3.10, p=.088\right)$. The Presentation effect was significant only by items $\left(F_{1}(1,4)=2.72, p=.17 ; F_{2}(1,29)=13.90, p=.001\right)$, and the interaction between Condition and Presentation was not significant ( $p>.1$ in both analyses).

Clearly, the Wernicke's aphasic participants show a different result pattern compared to the other two subject groups. At least a considerable part of the interaction between Subject Group and Condition should be attributed to this different result pattern of the Wernicke's patients: the direction of the Condition effect is reversed, compared to the control adult group. Note that lexical decisions given to the prime items were mostly correct $(98 \%)$. For the Wernicke's patients, the small facilitation effect in the overlap condition indicates that even when recognition of the primes has been achieved, co-activated candidates are not properly deactivated. They remain above resting level.

Fig. 2 and the statistical analyses showed a main effect of Presentation (and no interaction between Subject

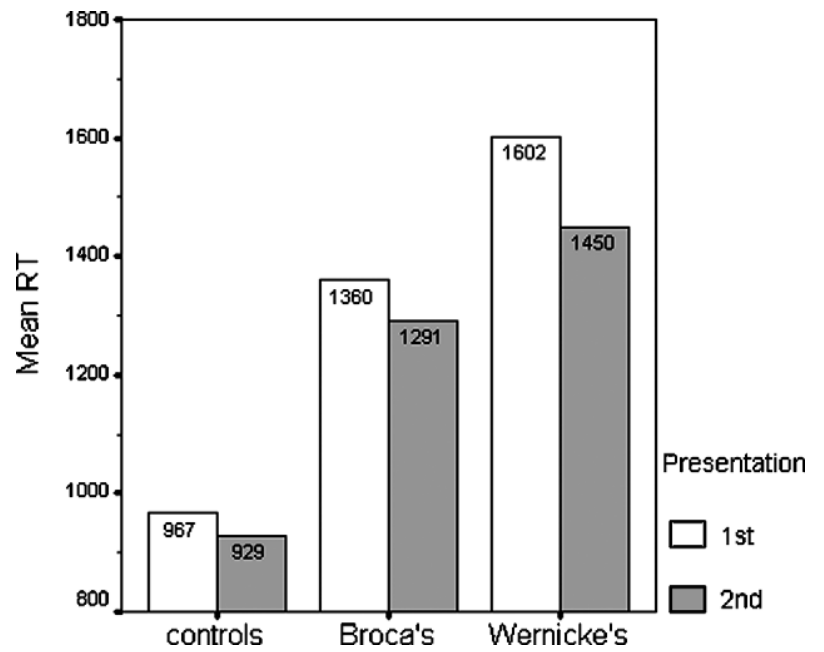

Fig. 2. Mean response time to targets at first and second presentation for the three subject groups.

Group and Presentation). These results are consistent with those of Blumstein et al. (2000) who also found significant repetition effects for Broca's and Wernicke's aphasic patients.

\section{Discussion}

Studies on access of words with multiple meanings have shown that both the right and left hemispheres may be involved in activation of semantic fields: the right hemisphere contributing to "coarse coding" of a broad semantic field and the left hemisphere contributing to "precision." Importantly, while both hemispheres can suppress inappropriate information to some degree (Faust \& Gernsbacher, 1996), the left hemisphere may be more efficient in suppression of 'irrelevant' activation: once multiple meanings have been accessed, the irrelevant ones must be deactivated (Burgess \& Simpson, 1988; Faust \& Gernsbacher, 1996; Nakagawa, 1991). Prather et al. (1997) investigated the time course of lexical activation in two aphasic patients by using a list priming paradigm in which the number of intervening stimuli between prime and semantically related target can be varied. They found a rapid decline of lexical activation for their Broca's patient, and a slowed decline for the Wernicke's patient. They therefore suggest that anterior regions of the left hemisphere might be involved in initiation (activation) and posterior regions with inhibition or "focusing in" with respect to lexical activation (Prather et al., 1997, p. 407). The results of the present study are consistent with this account: Broca's aphasic participants showed a weak pattern of inhibition (following activation) compared to the control adults, but the Wernicke's aphasic participants showed a lack of suppression effects. 
Several researchers have shown that initial activation of word candidates is reduced in Broca's aphasic patients (Milberg et al., 1988; Milberg, Blumstein, Katz, Gershberg, \& Brown, 1995; Blumstein et al., 2000), or slowed down (Prather et al., 1997; Prather, Zurif, Stern, \& Rosen, 1992). Even though the present set-up does not allow precise tracking of the time course of activation, the present results show some indirect evidence that longer words do activate multiple word candidates. Form-overlapping primes must have caused activation for the targets, given the weak trend for inhibition in the Broca's group. This agrees with the weak onset-competitor effects for Broca's aphasic patients found in Yee et al. (2004). Note, however, that the present results for the Broca's aphasic patient group were unequivocal (cf. Table 3): while a number of patients showed inhibition, other patients even showed facilitation in the overlap condition. Further research is required to draw stronger conclusions on activation and deactivation of word candidates in the Broca's aphasic group.

For the Wernicke's patients, on the other hand, word candidates do not seem to compete in such a way that just one candidate comes out as the winner ('at the cost' of deactivation of the other candidates). Thus, we are faced with a paradox: even though the intended prime word is recognised (proof for this being a correct lexical decision response), co-activated candidates are not properly deactivated, and remain above resting level. It is important to note that high accuracy scores on primes (or targets) do not necessarily imply that the recognition system has converged on a winning candidate. The one candidate with the highest amount of bottom-up support may be activated highest (the intended word), but co-activated candidates also remain active. The present set-up does not allow direct comparison of the facilitatory effects of overlap $(107 \mathrm{~ms}$, excluding patient W6) versus that of repetition of the same item $(124 \mathrm{~ms}$, excluding W6) because of the different number of intervening items: facilitation of co-activated candidates is found after one to five intervening filler items whereas the repetition effect can only be established between the two experimental blocks (about 130 intervening items). Whereas Milberg et al. (1988) found 'overactivation' in the sense that rhyming words (gat) activated the target item (cat) to the same extent as the word cat itself for the Wernicke's patients, this overactivation was not found by Baum (1997) or Blumstein et al. (2000). Further research would be necessary to address this issue of activation by initial overlap primes vs. identity primes. However, in terms of lexical processing, when several candidates remain somewhat active, even once they should have been long suppressed, this may impede comprehension, first at word level, but then later at higher levels as well (cf. Hagoort, Brown, \& Swaab, 1996; Swaab, Brown, \& Hagoort, 1997).

The present results on impaired inhibition in Wernicke's aphasia agree with the adapted Stroop Colour-
Word test results by Wiener et al. (2004). The Stroop interference effect, reflecting the inability to effectively ignore a distracting stimulus, was significantly larger for Wernicke's aphasic patients than for an age-matched control population. These findings support impaired inhibition at the lexical-semantic level.

Problems in inhibition may also exist on the speech production side in aphasia. Aphasic speakers sometimes produce perseverations in tasks such as picture naming: a previous response is inappropriately repeated. In a study on intrusions and perseverations in dementia patients, aphasic patients and a healthy control group, Shindler, Caplan, and Hier (1984) found that perseverations were most common in the Wernicke's aphasic patients (and in patients with dementia due to communicating hydrocephalus). Shindler et al. (1984) suggested that failure to self-monitor speech and an inability to change mental set may play a role in the generation of perseverations. Several other accounts have suggested that perseverations result when processing is too weak or slow to dominate a recently primed response. In particular, in anomic patients, if a different stimulus (picture) is presented, brain damage may degrade or deafferent this new input such that representations persisting in activity are not always overridden (e.g. Cohen \& Dehaene, 1998; Martin, Roach, Brecher, \& Lowery, 1998; Plaut \& Shallice, 1993). In line with this account, Gotts, Incisa della Rocchetta, and Cipolotti (2002) found that factors that weaken or slow the processing of a current stimulus, such as low-lexical frequency, give rise to more perseverations. However, given this balance between 'new' and 'old' activations, it seems more appropriate, for Wernicke's patients at least, to stress the abnormally high persisting activation because of deficient activation suppression.

To conclude, to complement the studies on impaired lexical access in Broca's aphasia, this study has suggested that lexical problems in Wernicke's aphasia mainly lie in impaired deactivation or selection among word candidates. Even after several intervening items, word candidates that no longer fit bottom-up information are not properly deactivated in Wernicke's aphasia.

Further research is necessary to investigate whether deactivation may be merely delayed in Wernicke's aphasia. The present results do not exclude this possibility. Furthermore, future research is needed to explore the relation between lexical access impairments in aphasic patients (differential impairments for Broca's and Wernicke's patients) on the one hand, and their auditory speech comprehension abilities on the other.

\section{Acknowledgments}

Thanks are due to the Dutch rehabilitation centres Heliomare, Blixembosch, Sophia Revalidatie, de 
Hoogstraat, het Roessingh, and het Rijnlands Revalidatiecentrum, and to the speech therapists working there, for their cooperation in this study. All aphasic patients and control participants are thanked for their time and effort. I thank my colleagues Sieb Nooteboom, Hugo Quené, and Esther Ruigendijk, and the reviewers for their valuable comments and suggestions.

\section{References}

Andruski, J., Blumstein, S. E., \& Burton, M. (1994). The effect of subphonetic differences on lexical access. Cognition, 52, 163-187.

Utman, J., Blumstein, S. E., \& Sullivan, K. (2001). Aydelott Mapping from sound to meaning: Reduced lexical activation in Broca's aphasics. Brain and Language, 79, 444-472.

Basso, A., Casati, G., \& Vignolo, L. A. (1977). Phonemic identification deficits in aphasia. Cortex, 13, 84-95.

Baum, S. R. (1997). Phonological, semantic, and mediated priming in aphasia. Brain and Language, 60, 347-359.

Blumstein, S. E., Cooper, W. E., Zurif, E. B., \& Caramazza, A. (1977). The perception and production of voice-onset time in aphasia. Neuropsychologia, 15, 371-383.

Blumstein, S. E., Milberg, W., Brown, T., Hutchinson, A., Kurowski, K., \& Burton, M. W. (2000). The mapping from sound structure to the lexicon in aphasia: Evidence from rhyme and repetition priming. Brain and Language, 72, 75-99.

Burgess, C., \& Simpson, G. B. (1988). Cerebral hemispheric mechanisms in the retrieval of ambiguous word meanings. Brain and Language, 33, 86-103.

Chwilla, D. J. (1996). Electrophysiology of word processing: The lexical processing nature of the $N 400$ priming effect. Doctoral dissertation. The Netherlands: Nijmegen University.

Cohen, L., \& Dehaene, S. (1998). Competition between past and present: Assessment and interpretation of verbal perseverations. Brain, $121,1641-1659$.

Connine, C. M., Blasko, D. G., \& Titone, D. (1993). Do the beginnings of spoken words have a special status in auditory word recognition? Journal of Memory and Language, 32, 193-210.

Csépe, V., Osman-Sági, J., Molnár, M., \& Gósy, M. (2001). Impaired speech perception in aphasic patients: Event-related potential and neuropsychological assessment. Neuropsychologia, 39, 1194-1208.

Cutler, A., \& van Donselaar, W. (2001). Voornaam is not (really) a homophone: Lexical prosody and lexical access in Dutch. Language and Speech, 44(2), 171-195.

Dufour, S., \& Peereman, R. (2003). Inhibitory priming effects in auditory word recognition: When the target's competitors conflict with the prime word. Cognition, 88, B33-B44.

Faust, M. E., \& Gernsbacher, M. A. (1996). Cerebral mechanisms for suppression of inappropriate information during sentence comprehension. Brain and Language, 53, 234-259.

Frauenfelder, U. H., Scholten, M., \& Content, A. (2001). Bottom-up inhibition in lexical selection: Phonological mismatch effects in spoken word recognition. Language and Cognitive Processes, 16(5/6), 583-607.

Gotts, S. J., Incisa della Rocchetta, A., \& Cipolotti, L. (2002). Mechanisms underlying perseveration in aphasia: Evidence from a single case study. Neuropsychologia, 40, 1930-1947.

Gordon, J. K., \& Baum, S. R. (1994). Rhyme priming in aphasia: The role of phonology in lexical access. Brain and Language, 47, 661-683.

Gow, D. W., \& Caplan, D. (1996). An examination of impaired acoustic-phonetic processing in aphasia. Brain and Language, 52, 386- 407.

Graetz, P., de Bleser, R., \& Willmes, K. (1992). Akense Afasietest $(A A T)$. Lisse (The Netherlands): Swets and Zeitlinger.
Hagoort, P., Brown, C. M., \& Swaab, T. Y. (1996). Lexical-semantic event-related potentials effects in patients with left-hemisphere lesions and aphasia, and patients with right-hemisphere lesions without aphasia. Brain, 119, 627-649.

Hasher, L., \& Zacks, R. T. (1988). Working memory, comprehension and aging: A review and a new view. In G. H. Bower (Ed.), The psychology of learning and motivation (Vol. 22). San Diego, CA: Academic Press.

Janse, E. (2003). Production and perception of fast speech. Doctoral dissertation. Utrecht (the Netherlands): Utrecht University, LOT Series.

Jongenburger, W. (1996). The role of lexical stress during spoken word processing. Dissertation. The Netherlands: Leiden University.

Leonard, C. L., \& Baum, S. R. (1997). The influence of phonological and orthographic information on auditory lexical access in braindamaged patients: A preliminary investigation. Aphasiology, 11(11), 1031-1041.

Marslen-Wilson, W., \& Zwitserlood, P. (1989). Accessing spoken words: On the importance of word onsets. Journal of Experimental Psychology: Human Perception and Performance, 15, 576-585.

Martin, N., Roach, A., Brecher, A., \& Lowery, J. (1998). Lexical retrieval mechanisms underlying whole-word perseveration errors in anomic aphasia. Aphasiology, 12, 319-333.

McClelland, J. L., \& Elman, J. L. (1986). The TRACE model of speech perception. Cognitive Psychology, 18, 1-86.

McQueen, J. M., \& Cutler, A. (2001). Spoken word access processes: An introduction. Language and Cognitive Processes, 16(5/6), 469-490.

Miceli, G., Gainotti, G., Caltagirone, C., \& Masullo, C. (1980). Some aspects of phonological impairment in aphasia. Brain and Language, 11, 159-169.

Milberg, W., Blumstein, S., \& Dworetzky, B. (1988). Phonological processing and lexical access in aphasia. Brain and Language, 34, 279-293.

Milberg, W., Blumstein, S., Katz, D., Gershberg, F., \& Brown, T. (1995). Semantic facilitation in aphasia: Effects of time and expectancy. Journal of Cognitive Neuroscience, 7(1), 33-50.

Misiurski, C., Blumstein, S. E., Rissman, J., \& Berman, D. (2005). The role of lexical competition and acoustic-phonetic structure in lexical processing: Evidence from normal subjects and aphasic patients. Brain and Language, 93(1), 64-78.

Monsell, S., \& Hirsch, K. W. (1998). Competitor priming in spoken word recognition. Journal of Experimental Psychology: Learning, Memory and Cognition, 24(6), 1495-1520.

Motta, G., Rizzo, F., Swinney, D., \& Piñango, M. M. (2000). Tempo: A software for psycholinguistic and neuroimaging testing. Brandeis University (Dept of Computer Science), University of California San Diego (Dept of Psychology) \& Yale University (Department of Linguistics).

Nakagawa, A. (1991). Role of anterior and posterior attention networks in hemispheric asymmetries during lexical decisions. Journal of Cognitive Neuroscience, 3(4), 313-321.

Neely, J. H., \& Keefe, D. E. (1989). Semantic context effects on visual word processing: A hybrid prospective/retrospective processing theory. In G. H. Bower (Ed.), The psychology of learning and motivation: Advances in research and theory (Vol. 24, pp. 207-248). New York: Academic Press.

Norris, D. (1994). Shortlist: A connectionist model of continuous speech recognition. Cognition, 52, 189-234.

Plaut, D. C., \& Shallice, T. (1993). Perseverative and semantic influences on visual object naming errors in optic aphasia: A connectionist account. Journal of Cognitive Neuroscience, 5, 89-117.

Prather, P. A., Zurif, E., Love, T., \& Brownell, H. (1997). Speed of lexical activation in nonfluent Broca's aphasia and fluent Wernicke's aphasia. Brain and Language, 59, 391-411.

Prather, P. A., Zurif, E., Stern, C., \& Rosen, T. J. (1992). Slowed lexical access in nonfluent aphasia: A case study. Brain and Language, 43, 336-348.

Shindler, A. G., Caplan, L. R., \& Hier, D. B. (1984). Intrusions and perseverations. Brain and Language, 23(1), 148-158. 
Slowiaczek, L. M., \& Hamburger, M. (1992). Prelexical facilitation and lexical interference in auditory word recognition. Journal of Experimental Psychology: Learning, Memory, and Cognition, $13,64-75$

Swaab, T. Y., Brown, C. M., \& Hagoort, P. (1997). Spoken sentence comprehension in aphasia: Event-related potential evidence for a lexical integration deficit. Journal of Cognitive Neuroscience, 9, 39-66.

Ulrich, R., \& Miller, J. (1994). Effects of truncation on reaction time analysis. Journal of Experimental Psychology: General, 123, 34-80.
Wiener, D. A., Connor, L. T., \& Obler, L. K. (2004). Inhibition and auditory comprehension in Wernicke's aphasia. Aphasiology, 18(5-7), 599-609.

Yee, E., Blumstein, S. E., \& Sedivy, J. (2004). The time course of lexical activation in Broca's and Wernicke's aphasia: Evidence from eyemovements. Brain and Language, 91, 62-63.

Yeni-Komshian, G., \& Lafontaine, L. (1983). Discrimination and identification of voicing and place contrasts in aphasic patients. Canadian Journal of Psychology, 37, 107-131. 